\title{
O terraço é o mundo: Vilém Flusser e o pensamento da compreensão
}

\author{
José Eugênio de Oliveira Menezes \\ Dimas A. Künsch
}

Resumo: O trabalho ocupa-se com as concepções do filósofo tcheco-brasileiro Vilém Flusser (19201991) a respeito dos termos diálogo e discurso nos processos comunicativos e problematiza a forma como essas noções oferecem elementos para os estudos e práticas de compreensão. A partir da autobiografia do autor (FLUSSER, 2007), publicada com o título alemão Bodenlos (sem chão ou sem fundamento), investiga sua formação como autodidata que teceu os fios da vida e dos conhecimentos no diálogo com um conjunto de interlocutores, com onze dos quais ele conversa na obra citada. Aborda as noções de diálogo, tenso e compreensivo, com o mundo em que se habita, do ensaio como forma de expressão do pensamento e da fala e escrita como opções de engajamento. Na medida em que o objetivo de Flusser era provocar novos pensamentos e ampliar a conversação, mostra como suas concepções contribuem para uma epistemologia compreensiva no universo da Comunicação.

Palavras-Chave: comunicação; cultura; diálogo; compreensão; Vilém Flusser.

Abstract: The balcony is the world: Vilém Flusser and the comprehensive thought - This paper discusses the concepts in the work of the Czech-Brazilian philosopher Vilém Flusser (1920-1991), regarding the terms dialogue and discourse in the communication processes and it questions how these notions could be a resource for the study and the practice of comprehension. Based on the author's autobiography (FLUSSER, 2007), published with the German title Bodenlos (with no ground or no foundation), this work investigates Flusser's autodidactic background, which took a major influence in his life and in his work when in dialogue with a group of interlocutors, being eleven of them mentioned in the aforementioned book. This paper also includes the notions behind the (tense and comprehensive) dialogue with the world one lives in, the essay as a means to express ideas and speaking and writing as options for engagement. As well as Flusser's goal was to provoke new thoughts and to amplify conversations; this text presents how his concepts could collaborate to a comprehensive epistemology of the Communication's universe.

Keywords: communication; culture; dialogue; comprehension; Vilém Flusser. 
Abrigo, abrigar, ser ou sentir-se abrigado. Estes são termos recorrentes na obra Bodenlos: uma autobiografia filosófica, de Vilém Flusser, o que pode num primeiro olhar aparecer como paradoxal na história de alguém que fez do não-fundamento, do desenraizamento, da Bodenlosigkeit uma condição de vida. Mais propriamente, o "sintoma de estar-se abrigado" (FLUSSER, 2007, p. 28), experimentado, lá atrás no tempo, em sua Praga natal, de onde teve que fugir, em 1939, aos 19 anos de idade. Assume, desse marco zero da vida sem fundamento em diante, a natureza de um diálogo existencialmente trágico com a experiência da solidão, do absurdo, do incessante questionamento de por que não se tirar a vida, na interlocução. Por outro lado, também com a esperança de que viver vale a pena, de que a busca da liberdade se faz urgente e necessária, de que amigos existem e que com eles a comunicação dialógica pode se fazer possível, de que a comunicação, enfim, nos arranca da solidão...

A expressão viver é perigoso, de um desses amigos e interlocutor brasileiro, Guimarães Rosa (1908-1967), em Grande Sertão: Veredas, assume, aqui, no sem-horizonte da Bodenlosikgeit, já a partir desse marco zero, toda a dramaticidade possível. Há que se optar entre a esperança de ser assassinado pelos invasores nazistas e a fuga como "sacrifício da dignidade em prol da sobrevivência do corpo", "uma decisão covarde", que deixaria no íntimo do fugitivo "a convicção irracional, mas existencialmente válida, de que, 'de direito'", dever-se-ia "ter morrido nos fornos", de que foi ele mesmo "que se arrancou de seu fundamento (dos fornos) ao ter fugido, e que, 'com razão' (?) o abismo sem fundo era o único futuro possível" (2007, p. 32).

Aos familiares, o forno. Tragicamente, mais uma vez, na consciência inquieta do jovem tcheco-judeu, "não foram os nazistas, foi a decisão para a fuga que matou a família da gente", escreve Flusser em sua autobiografia, cerca de 50 anos depois de essa decisão ser tomada. "Matou-a, para salvar a própria sombra, este corpo nojento. Nunca mais se podia ler o relato de Nietzsche sobre a morte de Deus, sem reconhecer-se nele" (2007, p. 33).

O texto que aqui se apresenta tem o objetivo ambicioso de identificar, na vida sem fundamento de Flusser (bondenloses Leben) e em seu pensamento, particularmente - mas não só - com base em sua autobiografia filosófica, um conjunto de traços, marcas, sinais ou símbolos de um viver e pensar compreensivos, como expressão de uma atitude ética e cognitiva dialógica.

Entende-se esse esforço como duplamente desafiador: tanto no sentido de que o vemos como apenas um início de uma conversa que pode ser bem mais ampla sobre o tema, quanto, já na linha de um pensamento compreensivo, como efeito do reconhecimento de que, como diz a escritora Clarice Lispector, "A vida não é lógica" e que essa vida, portanto, só num sentido bem restrito se deixa ver ou captar como objeto de especulação. 


\section{Ser abrigado e compreensão}

"A partir da visão atual", afirma Flusser ao redigir o texto de sua autobiografia, "sabe-se que naquele momento se estava encarando o rosto do Mal, que está à espreita logo debaixo da superfície em todo lugar e sempre, e que naquele momento foi apenas provocado pela presença nazista" (2007, p. 31). Ao trazer para a discussão o tema do "rosto do Mal", sempre à espreita, onipresente, o bodenloser Flusser se aproxima de outra fugitiva, quatorze anos mais velha que ele, Hannah Arendt (1906-1975), que fez desse mesmo tema, o Mal, e a partir do mesmo contexto histórico, o totalitarismo nazista, para além de uma preocupação de natureza filosófica, um verdadeiro tormento existencial.

O pesquisador brasileiro Gustavo Bernardo também tece relações entre os dois personagens. Mas os aproxima e diferencia ao mesmo tempo sob o fundamento da noção flusseriana de homens que atuam como funcionários de aparelhos - aliás, do segundo Flusser, depois de seu retorno à Europa, em 1972, quando passou a viver lá, já com a fama e o prestígio de "filósofo dos novos media" (BERNARDO, 2002, p. 176).

É possível, no entanto, retomar a noção de abrigo e de sentir-se abrigado, de que tratamos nas primeiras linhas deste texto, para perceber onde Arendt e Flusser dialogam um com o outro sob o manto daquilo que a primeira descrevia como uma necessidade imperiosa de compreensão. Referia-se, com frequência, ao "século terrível", o século $\mathrm{XX}$, ao "mundo não muito bonito", "ao mais sombrio de todos os tempos", e, mesmo quando incompreendida - como, especialmente, no caso de seu livro-reportagem sobre o julgamento do carrasco nazista Adolf Eichmann, Eichmann em Jerusalém: um relato sobre a banalidade do mal -, convocava para o gesto, "complexo que nunca gera resultados inequívocos", da compreensão. Compreender, continua Arendt, "é a maneira especificamente humana de viver, pois todo indivíduo precisa se sentir conciliado com um mundo onde nasceu como estranho e onde sempre permanece como estranho, na medida de sua singularidade única". Assim, "compreender o totalitarismo não é desculpar nada, mas nos conciliar com um mundo onde tais coisas são possíveis" (ARENDT, 2008, p. 331) .

A aproximação com o pensamento flusseriano se torna patente num capítulo de sua autobiografia que recebeu o título de "Habitar a casa na apatridade". Flusser refere-se ao "mistério" de sua "apatridade" e reassume, como em outras partes de sua obra, que, ao fugir, malgrado a dor, acabou depois sendo "acometido por aquela rara vertigem da libertação e da liberdade (Freisein), aquilo que, como se diz, caracteriza o espírito que flutua por todos os lugares" (2007, p. 223). A pátria, prossegue Flusser, depois de lembrar "o exemplo prosaico" do prato tcheco svickova (lombo assado), a saudosa, nostálgica pátria, traduz-se, no fundo e no raso, em "enraizamento" que acaba por se transformar em "enredamento obscurantista que é como um nó górdio a ser rompido" (2007, p. 224).

A história de vida dos dois fugitivos representa um testemunho eloquente do perigo que pode representar o viver, o pensar, o filosofar. "A violência começa onde termina 
a fala", afirma Arendt (2008, p. 331), que fez do pensamento, da escrita e da fala, de modo semelhante ao que fez Flusser, uma arma de resistência e luta.

Outras aproximações possíveis entre Flusser e Arendt dizem respeito aos modos como ambos interpretaram o papel do ensaio e os significados culturais e políticos da língua e do ato de escrever.

A abordagem escolhida poderá ser ampliada, em pesquisas futuras, na contextualização crítica de Flusser em relação a outros pensadores do século XX que, por diversos caminhos, ofereceram subsídios para uma epistemologia compreensiva da Comunicação ou problematizaram o alcance das possibilidades desta perspectiva. As consequências, por exemplo, do contato do autor com a postura filosófica idealista que se destacava nos debates do Instituto Brasileiro de Filosofia, fundado por Miguel Reale em 1949, é uma das perspectivas que podem gerar outras pesquisas.

\section{O terraço é o mundo}

Falar, escrever, travar um embate com a língua, as várias línguas e o português, particularmente, e fazer de tudo isso uma maneira de se sentir em casa e de habitar o mundo: Flusser dificilmente poderia não ser reconhecido como um exemplar desse humano ser. Páginas inteiras de sua autobiografia filosófica são dedicadas a considerações filosóficas, sintáticas e semânticas sobre as várias línguas que estudou, que falava e nas quais escrevia, dentre as quais o português, o alemão, o francês e o inglês se revelaram as mais importantes.

Ainda em Praga, dedicou-se ao estudo do espanhol para ler Ortega y Gasset. "Muito mais que a mensagem, a forma orteguiana fascinava a gente. Eis um modelo de escrever simples, econômico e penetrante" (2007, p. 73), ele conta, traduzindo um esforço que durou a vida toda em busca de um "estilo apropriado ao próprio ser-no-mundo" (2007, p. 73). Neste trecho, o Flusser fascinado pelo estilo orteguiano se refere ao aforismo; mais adiante, assumirá com todas as letras o estilo vivo do ensaio, no Brasil e no contato com a língua portuguesa:

Isto ia ser, doravante, o "estilo" da gente: três níveis rítmicos, com jogo praticamente ilimitado de simpatias e antipatias entre os níveis. Destarte, a língua portuguesa passou a ser instrumento apaixonante para jogo infinito, instrumento este que mudava, ele próprio, ao longo do jogo. E com isto a própria gente mudava. Em outros termos: a gente se transformava, disciplinada e entusiasticamente, em ensaísta brasileiro (2007, p. 82).

"A língua brasileira" (2007, p. 67-85) é um dos capítulos de Bodenlos. Nele o autor resume o contexto de sua ocupação atenta, responsável e amorosa com a língua portuguesa. O "grande rio da conversação" a que o Flusser se refere em Língua e realidade, 
uma obra específica sobre o tema da língua, compreende o diálogo fértil e contínuo com a língua, ou com as línguas. A meta é deixar que esse rio da conversação "seja levado pela correnteza da realização até o oceano do indizível" (2004, p. 201). O português brasileiro devia servir-lhe "como matéria-prima (...) para realizar a vida", sendo vivenciado "como desafio e como tarefa de vida". Um território a ser habitado: "Eis, pois, a situação na qual a gente se abria ao português, em resumo: ia ser a língua que devia ser absorvida para ser manipulada pelo alemão invadido pelo tcheco, latim, grego e hebraico, e pelo inglês, tendo Ortega por modelo. Tarefa, novamente, para toda uma vida. A vida recomeçava" (2007, p. 75).

Esse mesmo rio caudaloso da conversação compreende o escrever, sempre que possível, tanto quanto possível. "Falo e escrevo com entusiasmo. Falar e escrever são minha tara" (2007, p. 201), e "já que fui atingido pela praga da palavra, devo procurar transformar a tara em instrumento para a modificação do mundo e de mim mesmo" (2007, p. 202). Autodidata, sem diploma, pensador forjado no contato cru e doloroso com a vida, tecedor irrefreável de discursos e diálogos com amigos, alunos, intelectuais, artistas, deixou mais de trinta livros publicados e um invejável arsenal de artigos em revistas, periódicos científicos e jornais de todo o mundo. Durante anos frequentou com seus ensaios as páginas do Suplemento Literário de O Estado de S. Paulo. Escrevia, traduzia ele mesmo para o alemão, o inglês e o francês, ou do alemão e do inglês para o português, cultivando um estilo próprio.

Em Flusser, o bodenloser Flusser, o penso logo existo cartesiano desenha-se, em sua Bodenlosigkeit, como vivo, penso, falo, escrevo logo existo. Tenho moradia, casa, mesmo na apatridade. Língua como pátria, mátria, frátria, como canta Caetano Veloso, em "Língua": "A língua é minha pátria / eu não tenho pátria: tenho mátria / Eu quero frátria".

É no terraço de sua casa no bairro paulistano de Pinheiros - essa espécie de "ágora paulistana", como o descreve Gustavo Bernardo no Prefácio à autobiografia de Flusser (2007, p. 12) -, que, durante mais de duas décadas, os amigos se reúnem para o debate filosófico, o que tanto lembra os chamados "filósofos do jardim", seguidores de Epicuro, eles também apátridas, bodenlose Menschen (gente sem chão, sem fundamento), numa pátria invadida, impedida de ser: a Grécia, um dia clássica, mas naquele momento ocupada e dominada pelas forças macedônias (PESSANHA, 1992). A descrição do próprio Flusser oferece a dimensão da philia:

O olhar retrovertido, ou invertido, ou apontado na direção de São Paulo, contempla a cena do nosso terraço nos fins de semana. O terraço é elo orgânico entre jardim subtropical e uma série de salas abertas. É acessível apenas para quem atravessa a série de salas. O visitante, tendo passado pelo portão sempre aberto e a porta da casa quase sempre aberta, penetra vestíbulo que contrasta com o calor, a pressão e o barulho da rua e no qual o acolhem esboços em aquarela de Flexor. Daí passa para a sala cercada de obras da vanguarda brasileira e dominada por chapa de Mira, passa por uma pequena biblioteca e outra sala coberta de 
quadros para encontrar-se no terraço, geralmente sem ser visto pelos habitantes da casa. No terraço, dá de cara com os amigos empenhados em diálogo violento que formam círculo grande ou vários pequenos (2007, p. 193).

"E quem são os amigos e quem é o visitante?", pergunta-se o mesmo Flusser, para responder, na imensa parte reservada à memória em sua autobiografia:

\begin{abstract}
A retrospectiva focaliza um número de figuras que é excessivo para ser enquadrado no presente trabalho. Vê-se forçado, pois, a abandonar, com pesar e melancolia, a maioria delas. As figuras até aqui evocadas devem representar as demais, e representar, também, uma das camadas decisivas da cultura brasileira. Representam, com suas contradições, esperanças, decepções e atividades, uma cultura em busca de identidade e que começa a perder a esperança de encontrar-se consigo mesma (2007, p. 193).
\end{abstract}

As "figuras evocadas" são os onze nomes, sete brasileiros e quatro imigrantes (os artistas plásticos Samson Flexor, romeno, e Mira Shendel, suíça, citados na descrição que Flusser faz do terraço, são dois deles; Guimarães Rosa, como adiantamos, é um dos brasileiros), representantes "desse número excessivo" de amigos com quem o autor conversa, dialoga, em sua autobiografia (os onze perfis aparecem na parte da obra intitulada "Diálogos", que começa por fazer uma distinção entre "discurso e diálogo", tema que trataremos a seguir). A juventude, os alunos, os amigos dos filhos e amigos de amigos "formavam a maioria das pessoas reunidas".

No terraço, a vida pulsa. O social e o político, os contextos culturais não permitem ao pensar filosófico abstrair-se da vida para se situar nas nuvens. Há, no que diz respeito especialmente à juventude, um antes e um depois do Ato Institucional número 5 (Al-5) da Ditadura Militar. As frestas de esperança são de novo atravessadas pela faca de vários gumes da desesperança. Flusser se envolve, discute, objeta, discorda, propõe: não é uma unanimidade, porque não busca unanimidade alguma. Diálogos, ele irá explicar, são assim: produzem conhecimentos novos, não se resumem a simples trocas de informações. Um diálogo visceralmente engajado, nascido do sem-fundamento, e não detentor de qualquer promessa de sucesso no jogo complexo, difícil, dialético da compreensão. O terraço onde a vida pulsa e os diálogos se dão, assume simbolicamente o lugar da pátria ausente, necessária e desnecessária: o terraço é o abrigo impossível de não existir. O terraço, parafraseando Guimarães Rosa, é o mundo.

\title{
Discurso e diálogo
}

Em Bodenlos, na forma de ensaios que expõem a convivência com interlocutores, Flusser destaca a importância fundante do encontro com os outros. Considerando 
a ocorrência de encontros "raros", mas "alterantes", nos quais "a solidão para a morte vira solidão participada", sugere um modelo de vivência que procura captar a alteração "que se processa em mim (no interlocutor) durante tais encontros" (FLUSSER, 1983, p. 159).

O deixar-se alterar ou captar a alteração provocada pelo outro é uma postura que merece ser melhor observada. É possível que a própria condição de "sem chão" leve a esta postura, encaminhe para uma consciência de se estar em contínuo processo de engajamento nos discursos e diálogos. O esmero para se captar e narrar as alterações provocadas pelos encontros pode ser observado em cada capítulo da segunda parte de Bodenlos. Interessa-nos de forma particular a segunda parte - "Diálogos" - , aquela na qual as onze narrativas das relações com quatro imigrantes e sete brasileiros são abertas com o capítulo "Discurso e Diálogo" e concluídas com o capítulo "O Terraço". Se o capítulo de abertura apresenta uma espécie de investigação a respeito das noções de discurso e diálogo, o último retrata o ambiente de muitos dos encontros, isto é, o terraço da residência de Vilém e sua esposa Edith, na Rua Salvador Mendonça, 76, em São Paulo.

O exame das noções de discurso e diálogo é marcado pelos princípios da Teoria da Informação, bastante difundida no período, meados dos anos 1970. Assim, o discurso é "o processo pelo qual informações existentes são transmitidas por emissores, em posse de tais informações, para receptores que devem ser informados". Por outro lado, o diálogo "é processo pelo qual vários detentores de informações parciais e duvidosas (ou, em todo o caso, duvidadas) trocam tais informações entre si a fim de alcançar síntese que possa ser considerada informação nova" (2007, p. 89-90). O próprio autor, por outro lado, alerta que sua reflexão sobre discurso e diálogo segue um caminho diferente da "teoria da informação" ou da "informática" e que a teoria da comunicação deverá ser "entendida como uma disciplina interpretativa" e "a comunicação humana será abordada como um fenômeno significativo a ser interpretado" (2007b, p. 92).

Praticamente, em condições dialógicas, o que é visto de maneira privada acaba sendo compartilhado, isto é, "o que é visto subjetivamente tem de ser intersubjetivado" (2007b, p. 184). Nesse sentido, o diálogo pode ser concebido como uma situação na qual dois ou mais sistemas trocam informações, situação que pressupõe quatro condições prévias, conforme descritas no texto "Política e língua", publicado no jornal O Estado de S. Paulo, em 1968, e republicado na coletânea Ficções filosóficas, em 1998:

(a) os sistemas não podem ser idênticos ou muito semelhantes; (b) os sistemas não podem ser inteiramente ou quase inteiramente diferentes; (c) um dos sistemas não pode englobar ou quase englobar o outro; (d) os sistemas devem estar abertos para o outro (FLUSSER, 1998, p. 100).

O próprio autor apresenta exemplos das quatro condições (MENEZES, 2010). Como exemplo da primeira condição, na qual muitas vezes qualquer sentença ou afirmação 
é redundante, Flusser cita o caso de pessoas muito próximas ou casais quando não têm quase nada de novo a dizer um para o outro. Para ilustrar a segunda condição, fala sobre a incomunicabilidade entre um esquimó e um balula da África Central. As relações entre gerações são exemplos da terceira situação. Para mostrar a última condição, lembra o Muro de Berlim, contexto no qual um dos sistemas interrompeu o canal comunicante com o receio de que informações alterassem o repertório.

\section{A conversação com os quatro migrantes}

Ao redigir Bodenlos, o autor praticamente denuncia que o ambiente brasileiro das décadas de 1970 e 1980 estava marcado pelo excesso de discursos redundantes, que tentavam impor sistemas de concepção do mundo e pela raridade dos diálogos nos quais os interlocutores poderiam criar novas informações. Os quatro migrantes com os quais Flusser dialoga são Alex Bloch, Samson Flexor, Romy Fink e Mira Schendel. Com cada um deles, especialmente os que mais frequentaram o terraço, estabelece um clima de conversação.

O diálogo com o judeu praguense Alex Bloch tomava duas formas: falar a respeito de um livro, um quadro, uma ideia, um filme, ou falar a respeito deles mesmos. A amizade permitia que Bloch analisasse não apenas os escritos de Flusser, mas especialmente o clima existencial no qual Flusser os tinha escrito, tornando-se um crítico por excelência. É descrito como "o único interlocutor no clima da amizade e com carga feminina" (2007, p. 93), como um homem sem máscaras que vivia de aventura em aventura, como quem exerceu paradoxais atividades.

O artista plástico romeno Samson Flexor (1907-1971) é o autor da tela intitulada "Diálogo" que ilustra a capa do livro Vilém Flusser no Brasil (BERNARDO; MENDES, 2000). Com ele, um dos principais temas tratados foi o mal-estar diante das concepções marxistas que ambos conheciam muito bem. O fato de a tradição marxista, que chamava a um engajamento, conviver em Flexor com a formação em matemática e amplo conhecimento do cubismo, do abstracionismo, da música e da poesia, deixou em Flusser uma "lembrança inesquecível e (uma) tarefa inevitável" (2007, p. 127).

No final do texto a respeito do diálogo com artista plástico, Flusser recorda como, também pelas provocações filosóficas de Vicente Ferreira da Silva, aos poucos reduziu o engajamento na realidade brasileira. Com o amigo Flexor vivenciou uma rebelião contra o estabelecimento tanto da direita quando da esquerda, fato que foi importante na decisão de deixar o país em 1972, poucos meses depois da morte de Samson Flexor.

No diálogo com a artista plástica suíça Mira Schendel (1919 -1988), que residiu no Brasil a partir de 1949, Flusser mostra que exercitava sua pouca paciência e constata que, quando resistia à amiga, "voavam faíscas". Observa que Mira "vivia perifericamente" e que ele tinha a esperança de, por meio do relato registrado em Bodenlos, de ajudá-la a abrir-se para o mundo. 
No relato a respeito da interação com Romy Fink lembra que ele chegou a São Paulo nos anos 1950 e foi progressivamente revelando suas múltiplas habilidades, tais como profundos conhecimentos a respeito, por exemplo, de cabala, coreografia e Shakespeare. No contexto da amizade com Fink compreendem-se as reflexões de Flusser a respeito do olhar do outro e da intersubjetividade. Com ele o filósofo tcheco-brasileiro aprendeu a admirar a dimensão ritual do judaísmo, que torna santificada toda a vida, e percebeu que não conseguia entrar nesse clima ritual por não ser capaz de amputar sua "dimensão grega", sua "teoria" (2007, p. 173).

\section{A conversação com sete brasileiros}

Em Bodenlos destaca-se o diálogo com Milton Vargas. Flusser considera que os múltiplos campos de engajamento de Milton Vargas (1914-2011), engenheiro construtor de barragens e estradas, teórico de mecânica dos solos, professor da Escola Politécnica da USP, ensaísta no campo da filosofia da ciência e crítico literário, o fazem um homem integral e universal no sentido renascentista do termo, "um anacronismo na época atual da especialização e departamentalização" (2007, p. 99).

O diálogo com o poeta, tradutor e crítico literário Haroldo de Campos (1929-2003) é marcado pelo reconhecimento das experiências concretistas presentes, por exemplo, na obra Galáxias por ser composta por discursos-fluxos circulares, no sentido de cada discurso individual retornar sobre um tema inicial e no sentido que "toda a obra é um sistema circular no qual circulam sistemas-satélites, e o foco do sistema são as palavras a serem variadas" (2007, p. 114). Por outro lado, Flusser problematizava o engajamento da arte de Campos por considerar que "a deliberada introdução de modelos teóricos e ideológicos na práxis linguística destrói a sua concreticidade" (2007, p.146).

Os climas da convivência com a poetisa e tradutora Dora Ferreira da Silva (19182006), esposa do filósofo Vicente Ferreira da Silva, são formulados considerando que "a poesia de Dora emana a beleza da harmonia, a presença concreta da Dora, a beleza da dissonância sofrida".

A intensa convivência com o filósofo Vicente Ferreira da Silva (1916-1963) pode ser considerada um capítulo especial nas conversações de Flusser. Apresentado como um homem da leitura e do escrever, Vicente acolheu e incentivou a produção intelectual de Flusser. O diálogo, ou "combate feroz" (2007, p. 117) a respeito de temas como liberdade, paganismo, posturas reacionárias, judeu-cristianismo, entre outros, foi truncado com a morte do filósofo.

Se o diálogo com Vicente foi qualificado como um combate feroz, não foi mais simples a interação com filósofo Miguel Reale (1920-2006). Flusser o descreve como uma "pessoa política", catedrático de Filosofia do Direito e reitor da Universidade de São Paulo. Com ele discute a respeito da responsabilidade do engajamento do intelectual no contexto brasileiro. 
Com o diplomata e escritor João Guimarães Rosa (1908-1967), Flusser cultivou uma relação marcada pelo acordo fundamental quanto ao fato que o escrever é o único método para pessoas como ele e Rosa "realizarem a própria essência (que é a língua calada dentro da gente)" (2007, p. 137). Flusser, mesmo frisando que no diálogo com Rosa o único tema era a vida e obra do próprio escritor brasileiro, enfatiza sua contribuição à compreensão do homem do interior do Brasil, "protótipo de uma unio mystica entre o homem e a natureza", aquela que representa "uma das poucas vias abertas à humanidade para salvar-se da massificação profanizadora" (2007, 131).

O advogado José Bueno de Aguiar (1918-2001), um dos amigos mais próximos, é apresentado como "representante nobre do latifundiário decadente, com cultura enciclopédica, gosto refinado, normas de retidão e de comportamento ético e estético sofisticamente elaboradas, visão desapontada e por isto desideologizada da cena da atualidade" (2007, p. 163).

\section{O chão onde ensaio e dialogia se encontram}

O Vilém Flusser que, no trânsito entre os opostos complementares do desespero e do engajamento, decide se lançar no diálogo sem certezas com a língua portuguesa é o mesmo que, já desde os tempos de sua Praga distante, estudava espanhol e lia com prazer Ortega y Gasset, fascinado com a forma como ele se expressava, um "modelo de escrever" para Flusser, como adiantamos, "simples, econômico e penetrante" (2007, p. 73). A "disciplina" e o "entusiasmo" o transformariam, anos mais tarde, como também adiantado, em "ensaísta brasileiro", por opção (2007, p. 82). O ensaio adquire para o bodenloser Flusser o sentido de habitação, abrigo, e de vida, no confronto com a morte.

O Flusser ensaísta das páginas que, durante anos, escreveu para O Estado de S. Paulo e de sua vasta obra bibliográfica traduz para seu tempo o que expressa Maffesoli, em O conhecimento comum: introdução à sociologia compreensiva (2007) e em outras de suas obras, quando propõe à academia resistir "à infamante acusação de ensaísmo" para resgatar o poder, a força e a dignidade do ensaio, uma escrita "brilhante, polifônica e que, ao mesmo tempo, reflita sobre si própria" (2007, p. 42).

Outras vozes ligam o ensaio, na acepção alegre e ao mesmo tempo trágica que assume em Flusser, com a vida. Por exemplo, a voz seminal de Michel de Montaigne (1533-1592), o pai do ensaio moderno, que em um de seus textos mais famosos, "Sobre a experiência", torna patente essa ideia de que a vida se escreve no ensaio que, por sua vez, confere à vida os sentidos que a fazem compreensível (como proposto por Hannah Arendt) - e não, por certo, explicável. Ensaios é justamente o título de um dos textos publicados por Flusser em O Estado de S. Paulo no dia 19 de agosto de 1967, que é reproduzido como capítulo de Ficções filosóficas (FLUSSER, 1998, p. 93-97). O "estilo acadêmico" - cuja "beleza", embora também a questione, Flusser não nega: "É a beleza 
do rigor, que não é necessariamente um rigor mortis" (1998, p. 94) - é caracterizado por ele como "despersonalizado", enquanto para o ensaio Flusser reserva o adjetivo "vivo", ligado visceralmente à vida ("ensaio-vida").

A decisão pelo ensaio é um dos lugares privilegiados do encontro entre o bodenloser Flusser e Martin Buber (1878-1965) de Eu e tu (obra lançada em 1923): no terreno do diálogo. Ele distingue entre "tratado" - é assim que resolve denominar, sem maiores preocupações, o texto de estilo acadêmico - e ensaio, tocando o terreno amplo e profundo da intersubjetividade. O "tratado" explica, e o ensaio compreende, abraça, integra o eu e o assunto, o eu e o tu.

Essa dialogia, ou, como prefere Flusser, essa comunicação dialógica que o coloca frente ao outro-de-si-mesmo é uma constante das preocupações do filósofo tcheco-brasileiro. Ela aparece, com toda a força de sua expressão, de modo particularmente intenso, nas conversas que mantém no terraço de sua residência paulistana - "O terraço é o mundo".

Em sua juventude em Praga, Flusser conhecera Buber. "Junto com Edith Barth", a futura esposa - Flusser acompanhou a família de Edith em sua fuga, em 1939, para Londres, chegando no ano seguinte ao Brasil, onde se casariam -, "ele ouviu uma conferência de Martin Buber, que se transformou para ambos numa experiência marcante", descrevem Silvia Wagnermaier e Nils Röller, em Absolute Vilém Flusser (WAGNERMAIER \& RÖLLER, 2009, p.27).

A visão dialógico-compreensiva do ensaio e sua vinculação com a vida (sem fundamento), para encerrar esta parte, requer "honestidade existencial", argumenta Flusser. E o estilo acadêmico "reúne honestidade intelectual com desonestidade intelectual, já que quem a ele recorre empenha o intelecto e tira o corpo", continua. "Caracteristicamente evita o uso do pronome 'eu'. Substitui o 'eu' pelo bombástico (embora aparentemente modesto) 'nós', ou pelo 'se', que não compromete" (2007, p. 94). Em suma, no texto puro da academia, ortodoxamente - e não compreensivamente - pensado, o diálogo com a vida e com o outro não se dá. O "eu" - esse é o risco, de que o ensaio, para Flusser, não se livra automaticamente - vira "isso", ou, em termos buberianos, o eu contenta-se com o significado que manifesta na posição que ocupa na palavra-princípio "Eu-Isso". Mas o "Eu da palavra-princípio Eu-Tu é diferente daquele da palavra-princípio Eu-Isso" (BUBER, 2004, p. 53).

\section{A conversação continua}

As noções do diálogo tenso e compreensivo com o mundo em que se habita, do ensaio como forma de expressão do pensamento e da fala e escrita como opções de engajamento parecem-nos legitimar o estudo das obras de Flusser como contribuição para uma epistemologia compreensiva no universo da Comunicação. Esta percepção, que, na linha do que entendemos por ensaio, não pretende amarrar de forma conclusiva as noções apresentadas, deixa em aberto a continuidade da pesquisa e convida, ainda que de forma introdutória, à ampliação do leque de estudos aqui esboçado pela investigação das posturas de Flusser em relação ao pensamento da compreensão. 
Considerando que, nas palavras de Emmanuel Levinas, "compreender nossa situação no real não é defini-la, mas encontrar-se numa disposição afetiva, compreender é existir" (LEVINAS, 1997, p. 23), entendemos que a postura humana do bodenloser Vilém Flusser nos desafia ao engajamento, também pela escrita, na conversação.

Jose Eugenio de Oliveira Menezes é docente do Programa de Pós-Graduação em Comunicação da Faculdade Cásper Líbero. Integra o Grupo de Pesquisa Comunicação e Cultura do Ouvir. É graduado em jornalismo e filosofia, mestre pela PUC/SP e doutor pela ECA/USP.

menezes.eugenio@gmail.com

Dimas A. Künsch é docente do Programa de Pós-Graduação em Comunicação da Faculdade Cásper Líbero.

dimaskunsch@casperlibero.edu.br

\section{Referências}

ADORNO, T. O ensaio como forma. In: COHN, Gabriel. Theodor W. Adorno. São Paulo: Ática, 1986, p. 167-187.

ARENDT, H. Compreender: formação, exílio e totalitarismo. São Paulo: Companhia das Letras, 2008.

Eichmann em Jerusalém: um relato sobre a banalidade do mal. Trad. José Rubens Siqueira. São Paulo: Companhia das Letras, 2003.

BAITELLO, N. A terceira catástrofe do homem ou as dores do espaço, a fotografia e o vento. Flusserstudies.net, Lugano, n. 3, 2006. Disponível em: < http://www.flusserstudies.net/sites/www. flusserstudies.net/files/media/attachments/terceira-catastrofe-homem.pdf> . Acesso em: 10 fev. 2016.

BERNARDO, G. A dúvida de Flusser: filosofia e literatura. São Paulo: Globo, 2002.

BERNARDO, G.; MENDES, R. (Orgs.). Vilém Flusser no Brasil. Rio de Janeiro: Relume Dumará, 2000.

FLUSSER, V. Pós-história: vinte instantâneos e um modo de usar. São Paulo: Duas Cidades, 1983.

1994.

Von der Freiheit des Migranten: Einsprüche gegen den Nationalismus. Bensheim: Bollmann,

Ficções Filosóficas. São Paulo: Edusp, 1998.

Bodenlos: uma autobiografia filosófica. São Paulo: Annablume, 2007.

O mundo codificado. Org. Rafael Cardoso.São Paulo: Cosac Naif, 2007b.

. Língua e realidade. São Paulo: Annablume, 2004.

Ser judeu. São Paulo: Annablume, 2014. 
KÜNSCH, D. A. Comunicação e pensamento compreensivo: um breve balanço. In: KÜNSCH, D. A.; MARTINO, L. M. S. (Orgs.). Comunicação, jornalismo e compreensão. São Paulo: Plêiade, 2010. Disponível em: < http://casperlibero.edu.br/mestrado/livros-mestrado/\#> . Acesso em: 10 fev. 2016.

LEVINAS, E. Entre nós: ensaios sobre a alteridade. Petrópolis: Vozes, 1997.

MAFFESOLI, M. A contemplação do mundo. Porto Alegre: Artes e Ofícios, 1995.

O conhecimento comum: introdução à sociologia compreensiva. Porto Alegre: Sulina, 2007.

MENEZES, J. E. O. Para ler Vilém Flusser. Líbero, São Paulo, v. 13, n. 25, p. 19-30, 2010.

. Comunicação, Espaço e Tempo: Vilém Flusser e os processos de vinculação. Comunicação, Mídia e Consumo, São Paulo. v. 6, n. 15, p.11-196, 2009.

. Comunicação dialógica e comunicação discursiva em Vilém Flusser. In: COSTA, M. J. (Org.). A festa da língua: Vilém Flusser. São Paulo: Fundação Memorial da América Latina, 2010.

MONTAiGnE, M. "Sobre a experiência". In: Ensaios. São Paulo: Companhia das Letras, 2010, p. 508-583.

PESSANHA, J. A. M. As delícias do jardim. In: NOVAES, A. (Org.). Ética. São Paulo: Companhia das Letras, 1992, p. 57-85.

WAGNERMAIER, S.; RÖLLER, N. Absolute Vilém Flusser. Freiburg: Orange Press, 2009.

Artigo recebido em agosto e aprovado em outubro de 2016. 